\title{
Overgrowth syndromes and pediatric cancers: how many roads lead to IGF2?
}

\author{
Ruthrothaselvi Bharathavikru and Nicholas D. Hastie \\ Medical Research Council, Human Genetics Unit, Institute of Genetics and Molecular Medicine, University of Edinburgh, \\ Western General Hospital, Edinburgh EH4 2XU, United Kingdom
}

\begin{abstract}
Overgrowth syndromes such as Perlman syndrome and associated pediatric cancers, including Wilms tumor, arise through genetic and, in certain instances, also epigenetic changes. In the case of the BeckwithWiedemann overgrowth syndrome and in Wilms tumor, increased levels of IGF2 have been shown to be causally related to the disease manifestation. In the previous issue of Genes \& Development, Hunter and colleagues (pp. 903-908) investigated the molecular mechanisms by which mutations in the gene encoding the RNA degradation component DIS3L2 lead to Perlman syndrome. By analyzing nephron progenitor cells derived from their newly created Dis 312 mutant mouse lines, the investigators showed that DIS3L2 loss of function leads to up-regulation of IGF2 independently of the let7 microRNA pathway. In a second study in this issue of Genes \& Development, Chen and colleagues (pp. 996-1007) show that microRNA processing gene mutations in Wilms tumor lead to an increase in the levels of transcription factor pleomorphic adenoma gene 1 (PLAG1) that in turn activates IGF2 expression. Thus, augmented IGF2 expression seems to be a common downstream factor in both tissue overgrowth and Wilms tumor through several alternative mechanisms.
\end{abstract}

Overgrowth syndromes, including Beckwith-Wiedemann syndrome (BWS), Simpson-Golabi-Behmel syndrome (SGBS), and Perlman syndrome, are characterized by macrosomia, facial dysmorphism, intellectual disabilities, and, in some cases, renal abnormalities as well as heart defects (for review, see Kamien et al. 2018). These arise through genetic alterations, including chromosomal

[Keywords: DIS3L2; IGF2; LIN28; Perlman syndrome; Wilms tumor; microRNA; pediatric cancer]

Corresponding author: nick.hastie@igmm.ed.ac.uk

Article is online at http://www.genesdev.org/cgi/doi/10.1101/gad.317792.

118. Freely available online through the Genes \& Development Open Access option. translocations, loss of imprinting, duplication, or mutations resulting in altered expression of key developmental genes. Patients with these overgrowth syndromes also have a predisposition to tumors, particularly the pediatric kidney cancer Wilms tumor. However, individuals with BWS and SGBS may also develop other tumors, including hepatoblastoma and neuroblastoma. It is well established that BWS arises through increased expression of the imprinted IGF2 gene through either paternal 11p15 disomy or loss of imprinting of the maternal allele. Furthermore, increased expression of IGF2 through these mechanisms is commonly found as a somatic event in Wilms tumors. Work with animal models has provided evidence that increased IGF2 expression is an important contributing factor in both BWS and Wilms tumor (Caspary et al. 1999; Hu et al. 2011; Huang et al. 2016). Two studies, Chen et al. (2018) in this issue and Hunter et al. (2018) in the previous issue of Genes \& Development, highlight the significance of IGF2 up-regulation in the context of Perlman syndrome and Wilms tumor, respectively.

Hunter et al. (2018) addressed the mechanisms underlying Perlman syndrome, which is an autosomal recessive syndrome arising through mutation of DIS3L2 on chromosome 2q37 (Astuti et al. 2012). DIS3L2 functions as a $3^{\prime}-5^{\prime}$ exoribonuclease that preferentially degrades oligouridylated RNAs (Lubas et al. 2013). In this context, DIS3L2 has been shown to be the only known exoribonuclease for degrading preprocessed forms of microRNA let7 (Chang et al. 2013). Recent genetic evidence has shown microRNA processing gene (MIRPG) mutations associated with Wilms tumor (Rakheja et al. 2014; Torrezan et al. 2014; Walz et al. 2015; Wegert et al. 2015), characterized by dysregulated microRNA levels. Moreover, microRNA let7 is known to function as a Wilms

(C) 2018 Bharathavikru and Hastie This article, published in Genes \& Development, is available under a Creative Commons License (Attribution 4.0 International), as described at http://creativecommons.org/licenses/ by $/ 4.0 /$. 
tumor suppressor in a mouse model through inhibition of the oncogenic target lin28, which is overexpressed in Wilms tumor (Viswanathan et al. 2009; Urbach et al. 2014).

Accordingly, the investigators tested the hypothesis that DIS3L2 loss of function leads to alteration in let7 levels in both human cell lines and mouse model systems. Using genome editing, series of DIS3L2-null human cell lines as well as knockout mouse embryonic stem cells were created. In neither case was any change in the expression of the microRNA let7 family members observed. With the help of a CRISPR/Cas9 approach, a Dis312-null mouse strain was generated by deleting the catalytic domain as well as a strain that models a common exon deletion found in Perlman patients. Further analysis showed that this latter mutation results in a destabilized protein and is functionally null. In the case of both alleles, homozygous mutant animals were perinatal lethal. Embryonic day $18.5 \mathrm{em}$ bryos exhibited some of the features of Perlman syndrome, including bradykinesia, abnormal curvature of the spine, and highly penetrant genitourinary (GU) abnormalities. However, there was no overgrowth or evidence of kidney abnormalities or Wilms tumor. Wilms tumors arise from the uninduced metanephric mesenchyme, where the Wilms tumor 1 (WT1) gene is expressed. An earlier study showed that overexpression of RNA-binding protein lin28 results in Wilms tumor (Urbach et al. 2014) only if the overexpression was driven using a $W t 1^{\text {cre }}$ line. Hence, to bypass lethality and further investigate the propensity of the Dis3l2 mutant animals to form Wilms tumors, the investigators crossed a floxed Dis312 line with a $W t 1^{\text {cre }}$ line. The resulting mutant animals in this case survived to adulthood but did not exhibit overgrowth or Wilms tumor, indicating that loss of Dis312 alone is not sufficient for the tumor formation.

To investigate the mechanism, the investigators used state-of-the-art approaches to develop nephron progenitor cells (NPCs) from the mutant mice. As for the cell lines, the Dis312 mutant NPCs did not show any change in mature let7 microRNA levels. However, RNA sequencing analysis of the NPCs revealed a severalfold increase in Igf2 expression. Hunter et al. (2018) show that the increased Igf2 level is transcriptional and does not seem to be due to any genetic or epigenetic changes associated with the H19/Igf2 locus. Given the precedents established in human Wilms tumors and mouse models, this level of up-regulation of Igf2 would be sufficient to play a causal role in tumorigenesis. However, interestingly, three of the four Wilms tumors that developed in Perlman patients also had loss of imprinting or loss of heterozygosity of IGF2 (Wegert et al. 2015; Gadd et al. 2017), implicating an additive effect. It is not surprising that Wilms tumors did not develop in the Dis312 mutant mice because it has been shown that, in mouse models, Wilms tumor arises only if Igf2 up-regulation is on the background of additional mutations, such as in Wt1 (Hu et al. 2011; Huang et al. 2016). The absence of over- growth phenotype in these mutants could be because of species- and tissue-specific promoter usage, which needs to be investigated separately. Clearly, as Igf2 up-regulation is at the transcriptional level, loss of exoribonuclease DIS3L2 must be acting on upstream RNA targets. The transcriptome data on the mutant NPCs should be an informative resource to identify such upstream regulators.

In another interesting study in this issue of Genes \& Development, Chen et al. (2018) elucidated a regulatory network by which altered microRNA levels may lead to Wilms tumor. Recent studies have shown that in 20\% of Wilms tumors, mutations of MIRPGs is observed, resulting in altered microRNA levels. Chen et al. (2018) show that pleomorphic adenoma gene 1 (PLAG1) is one of the consistently overexpressed genes in Wilms tumor, where MIRPG mutations are seen. The $3^{\prime}$ untranslated region analysis of PLAG1 showed microRNAbinding sites for $5 p$ microRNAs, miR34, and miR16, which are down-regulated in Wilms tumor. PLAG1 is a known transcription factor, and one of its important target genes in both disease and development is IGF2 (Declercq et al. 2008).

In order to understand the role of PLAG1 in kidney development, mouse models were created in which Plag1 was overexpressed in the developing kidney mesenchyme using $W t 1^{\text {cre }}$ and Six $1^{\text {cre }}$ drivers. In both cases, there was an overexpression of PLAG1 in the kidneys, which resulted in abnormal cysts with neoplastic characteristics. This was associated with up-regulation of Igf2 in the affected tissue. In a Wilms tumor cell line, the investigators replicated these findings, in which down-regulation of miR16/34 results in up-regulation of PLAG1, which transactivates $I g f 2$ expression. This increase in Igf2 leads to activation of the mTORC1 signaling pathway. This is also true in the Plag1 mouse models, where the cysts show positive expression for PLAG1 and activated mTORC1 pathway, whereas the surrounding kidney cells are devoid of this expression. In agreement with these findings, it appears that PLAG1 overexpression in Wilms tumors may alternatively arise through genetic, epigenetic, or post-transcriptional mechanisms that most likely manifest as an increase in Igf2 expression. The investigators also speculate on the possibility of using mTORC1 inhibitors or microRNA-based therapeutic strategies in Wilms tumor based on their observations.

Figure 1 summarizes the different mechanisms that converge on Igf2 up-regulation, leading to overgrowth and/or Wilms tumor. Unraveling the complex molecular details associated with the overgrowth syndromes and pediatric cancers has been largely possible due to the ability to create mouse models that replicate some of the disease phenotypes. It is now important to determine whether the same mechanisms operate and contribute to the phenotypes in humans. The recent advances in genome editing coupled with embryonic stem/induced pluripotent stem cell-derived organoid cultures should now make this possible. 


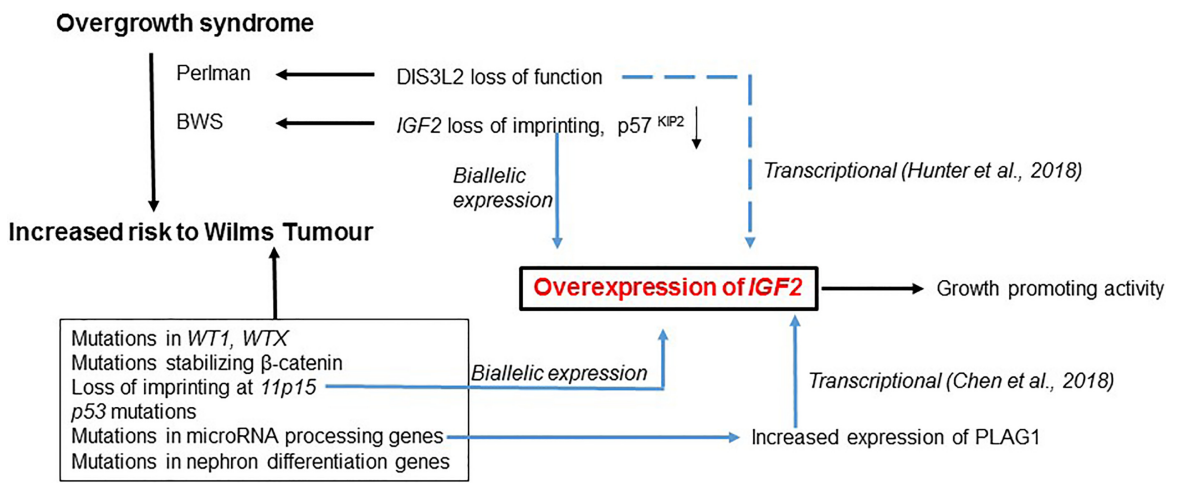

Figure 1. Multiple mechanisms that up-regulate IGF2 expression in overgrowth syndrome and associated pediatric cancer. The overgrowth syndrome BWS arises due to genetic and epigenetic changes in IGF2, whereas a second overgrowth syndrome, Perlman, is caused by mutations in the gene encoding the DIS3L2 exoribonuclease. Loss of DIS3L2 results in an up-regulation of Igf2. Patients with Perlman syndrome show an increased predisposition to Wilms tumor. Different categories of mutations have been identified in Wilms tumor. Among these, loss of imprinting at the 11p15 locus results in overexpression of IGF2. Mutations in the MIRPGs also lead to an up-regulation of IGF2 through overexpression of transcription factor PLAG1.

\section{Acknowledgments}

We thank Medical Research Council (MRC) Core Funding to the Human Genetics Unit and MRC grant MR/N020405/1 for funding.

\section{References}

Astuti D, Morris MR, Cooper WN, Staals RH, Wake NC, Fews GA, Gill H, Gentle D, Shuib S, Ricketts CJ, et al. 2012. Germline mutations in DIS3L2 cause the Perlman syndrome of overgrowth and Wilms' tumor susceptibility. Nat Genet 44: 277-284.

Caspary T, Cleary MA, Perlman EJ, Zhang P, Elledge SJ, Tilghman SM. 1999. Oppositely imprinted genes p57(Kip2) and igf2 interact in a mouse model for Beckwith-Wiedemann syndrome. Genes Dev 13: 3115-3124.

Chang HM, Triboulet R, Thornton JE, Gregory RI. 2013. A role for the Perlman syndrome exonuclease Dis312 in the Lin28-let-7 pathway. Nature 497: 244-248.

Chen KS, Stroup EK, Budhipramono A, Rakheja D, NicholsVinueza D, Xu L, Stuart SH, Shukla AA, Fraire C, Mendell JT, et al. 2018. Mutations in microRNA processing genes in Wilms tumors derepress the IGF2 regulator PLAG1. Genes Dev (this issue). doi: 10.1101/gad.313783.118.

Declercq J, Van Dyck F, Van Damme B, Van de Ven WJ. 2008. Upregulation of Igf and Wnt signalling associated genes in pleomorphic adenomas of the salivary glands in PLAG1 transgenic mice. Int J Oncol 32: 1041-1047.

Gadd S, Huff V, Walz AL, Ooms AHAG, Armstrong AE, Gerhard DS, Smith MA, Auvil JMG, Meerzaman D, Chen QR, et al. 2017. A Children's Oncology Group and TARGET initiative exploring the genetic landscape of Wilms' tumor. Nat Genet 49: 1487-1494.

Hu Q, Gao F, Tian W, Ruteshouser EC, Wang Y, Lazar A, Stewart J, Strong LC, Behringer RR, Huff V. 2011. Wt1 ablation and Igf2 upregulation in mice result in Wilms' tumors with elevated ERK1/2 phosphorylation. J Clin Invest 121: 174-183.

Huang L, Mokkapati S, Hu Q, Ruteshouser EC, Hicks MJ, Huff V. 2016. Nephron progenitor but not stromal progenitor cells give rise to Wilms' tumors in mouse models with $\beta$-catenin activation or Wt1 ablation and Igf2 upregulation. Neoplasia 18: 71-81.
Hunter RW, Liu Y, Manjunath H, Acharya A, Jones BT, Zhang H, Chen B, Ramalingam H, Hammer RE, Xie Y, et al. 2018. Loss of Dis312 partially phenocopies Perlman syndrome in mice and results in up-regulation of Igf2 in nephron progenitor cells. Genes Dev 32: 903-908.

Kamien B, Ronan A, Poke G, Sinnerbrink I, Baynam G, Ward M, Gibson WT, Dudding-Byth T, Scott RJ. 2018. A clinical review of generalized overgrowth syndromes in the era of massively parallel sequencing. Mol Syndromol 9: 70-82.

Lubas M, Damgaard CK, Tomecki R, Cysewski D, Jensen TH, Dziembowski A. 2013. Exonuclease hDIS3L2 specifies an exosome-independent $3^{\prime}-5^{\prime}$ degradation pathway of human cytoplasmic mRNA. EMBO I 32: 1855-1868.

Rakheja D, Chen KS, Liu Y, Shukla AA, Schmid V, Chang TC, Khokhar S, Wickiser JE, Karandikar NJ, Malter JS, et al. 2014. Somatic mutations in DROSHA and DICER1 impair microRNA biogenesis through distinct mechanisms in Wilms' tumors. Nat Commun 2: 4802.

Torrezan GT, Ferreira EN, Nakahata AM, Barros BD, Castro MT, Correa BR, Krepischi AC, Olivieri EH, Cunha IW, Tabori U, et al. 2014. Recurrent somatic mutation in DROSHA induces microRNA profile changes in Wilms' tumor. Nat Commun 5: 4039.

Urbach A, Yermalovich A, Zhang J, Spina CS, Zhu H, PerezAtayde AR, Shukrun R, Charlton J, Sebire N, Mifsud W, et al. 2014. Lin28 sustains early renal progenitors and induces Wilms' tumor. Genes Dev 28: 971-982.

Viswanathan SR, Powers JT, Einhorn W, Hoshida Y, Ng TL, Toffanin S, O'Sullivan M, Lu J, Phillips LA, Lockhart VL, et al. 2009. Lin 28 promotes transformation and is associated with advanced human malignancies. Nat Genet 41: 843-848.

Walz AL, Ooms A, Gadd S, Gerhard DS, Smith MA, Guidry Auvil JM, Meerzaman D, Chen QR, Hsu CH, Yan C, et al. 2015. Recurrent DGCR8, DROSHA, and SIX homeodomain mutations in favorable histology Wilms' tumors. Cancer Cell 27: 286-297.

Wegert J, Ishaque N, Vardapour R, Geörg C, Gu Z, Bieg M, Ziegler B, Bausenwein S, Nourkami N, Ludwig N, et al. 2015. Mutations in the SIX1/2 pathway and the DROSHA/DGCR8 miRNA microprocessor complex underlie high-risk blastemal type Wilms' tumors. Cancer Cell 27: 298-311. 


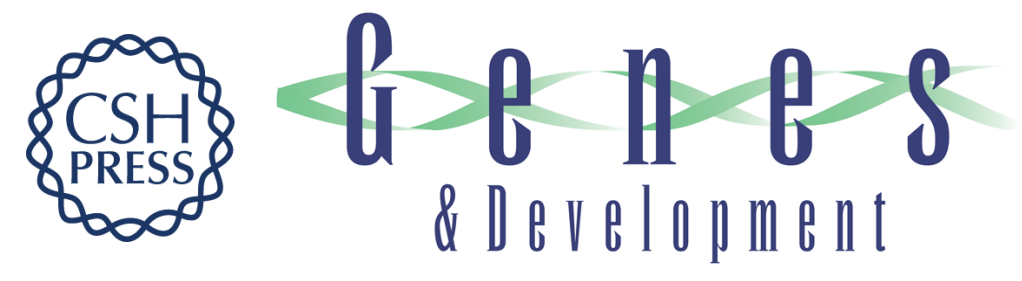

\section{Overgrowth syndromes and pediatric cancers: how many roads lead to IGF2?}

Ruthrothaselvi Bharathavikru and Nicholas D. Hastie

Genes Dev. 2018, 32:

Access the most recent version at doi:10.1101/gad.317792.118
Related Content Mutations in microRNA processing genes in Wilms tumors derepress the IGF2 regulator PLAG1
Kenneth S. Chen, Emily K. Stroup, Albert Budhipramono, et al.
Genes Dev. August , 2018 32: 996-1007 Loss of Dis312 partially phenocopies Perlman syndrome in mice and results in up-regulation of Igf2 in nephron progenitor cells Ryan W. Hunter, Yangjian Liu, Hema Manjunath, et al.
Genes Dev. July , 2018 32: 903-908
References This article cites 17 articles, 5 of which can be accessed free at:
http://genesdev.cshlp.org/content/32/15-16/993.full.html\#ref-list-1
Articles cited in:
http://genesdev.cshlp.org/content/32/15-16/993.full.html\#related-urls
Creative This article, published in Genes \& Development, is available under a Creative Commons Commons License License (Attribution 4.0 International), as described at http://creativecommons.org/licenses/by/4.0/.
Email Alerting Service

